\title{
San Romerio - Porträt einer Alp
}

\section{Erhard Taverna}

Dr. med., Mitglied der Redaktion

Im Eröffnungsbild gleitet unser Blick über die zerklüftete Felswand nach oben zur Abbruchkante. Eine Stimme erzählt vom Felssturz, der am Ende der Eiszeit in die Tiefe donnerte. Achthundert Meter Fallhöhe sind es von der kleinen Bergkirche San Romerio oder San Remigio am Abgrund, bis zum blauen Lago di Poschiavo. Rolf Haller, bis 2011 Kinderarzt im Kantonsspital Münsterlingen, hat den Film in seiner Retraite geschaffen.

Das Porträt einer abgelegenen Alp mit einer tausendjährigen Kirche und drei Häusern im Puschlav, nahe der Schweizergrenze zu Italien. In ruhigen Bildern erzählt der Film von früher und von heute. Von Gino Bongulielmi, dem Wirt und vielseitigen Handwerker, der mit seiner fleissigen Familie ein eigenhändig ausgebautes Berggasthaus betreibt.

Säumer, Söldner, Flüchtende und Mönche zogen im Spätmittelalter hier vorbei. Heute bevölkern Wandergäste den Wiesengrund am Fuss des Cornasc mit Blick auf das im Süden gelegene Veltlin. Ein jährliches Alpfest mit einer Messe für die Italiener und Schweizer der Region ersetzt heute die früheren Prozessionen. Der Film gibt Chronisten aus Brusio und Tirano das Wort, die in kurzen Kommentaren die jahrhundertealte Ortsgeschichte erläutern. Die Legende von Remi-

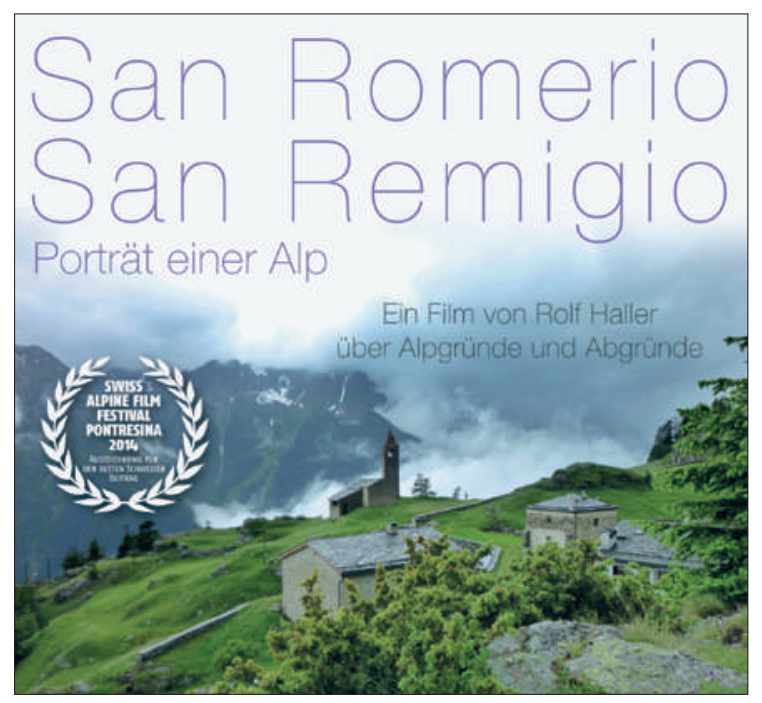

San Romerio - eine ausgezeichnete Verfilmung.

gius aus dem 5. Jahrhundert, des späteren Bischofs von Reims, der auf der Alp in einer Grotte Zuflucht vor seinen Verfolgern fand, wird in verfremdeten Bildern dargestellt. Eine zweite nachempfundene legendäre Filmszene erinnert an das klösterliche Leben der Schwestern und Mitbrüder, die zwischen 1200 und 1300 hier oben ein Hospiz unterhielten, die Alp rode-

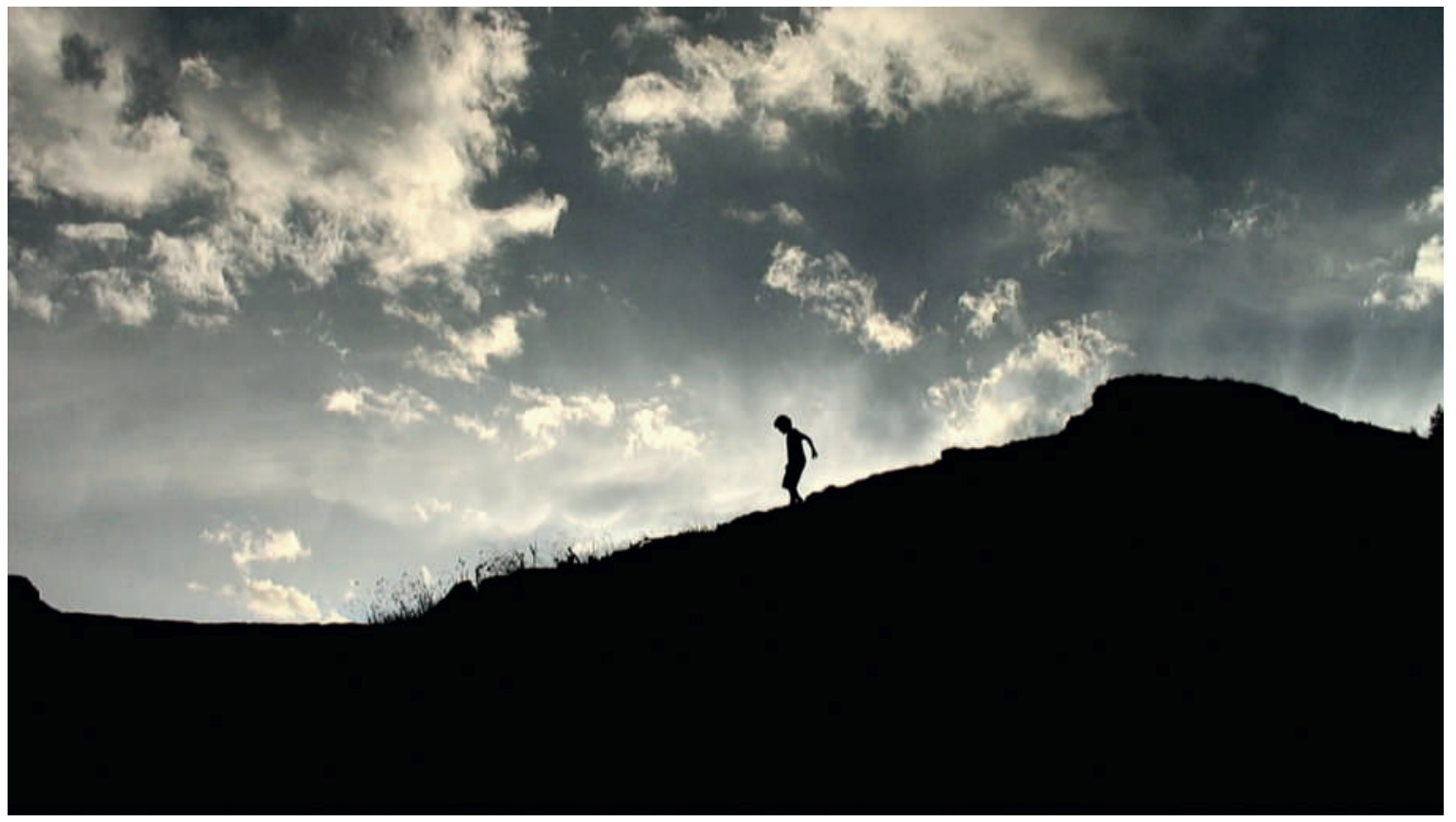

Rolf Haller als Achtjähriger im Jahr 1947 auf San Romerio. 


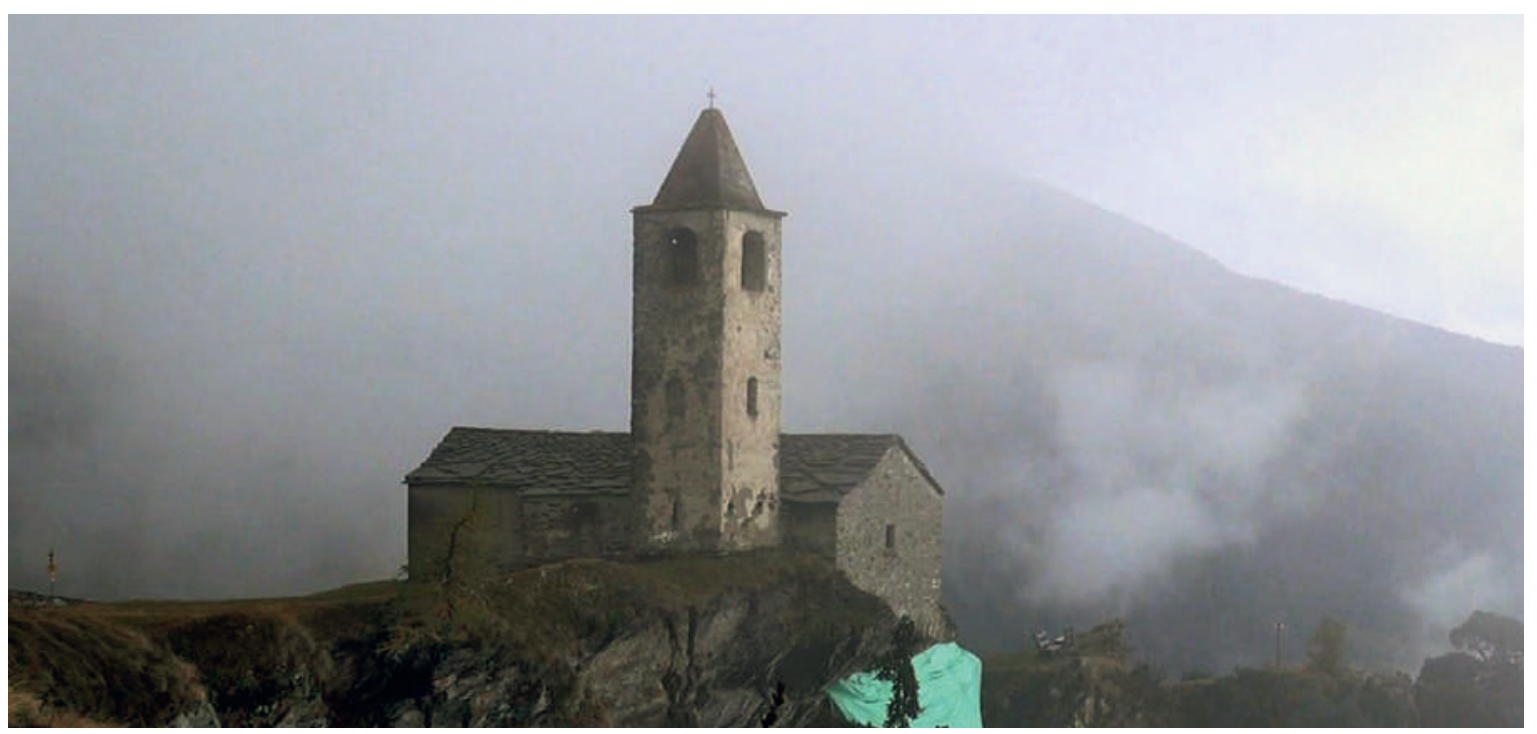

Die kleine Bergkirche von San Romerio.

ten, Gerste und Weizen anbauten. Ein Saumweg führte über Viano zum Berninapass, der gleiche, auf dem ein Schweizer Grenzwächter 1980 ein ägyptisches Eisenkreuz aus dem Mittelalter unter einer Marmorplatte entdeckte.

Geschickt verwebt Haller Jahreszeiten und Jahrhunderte, kleine und grosse Geschichten, zu einer faszinierenden, vielschichtigen Alpensaga, sensibel vom Saxophon des jungen Musikers Sam Urscheler begleitet, der hier mit seinem ersten Filmbeitrag seine Begabung zeigt. Ein Schweben an der Baumgrenze, wo im Rhythmus der Klänge das Wetter umschlägt. Nebel und Wolken verhüllen den Bergwald, Dohlen krächzen im Schwarm, der Wind heult, einsam ragt der kleine Kirchturm in die wildgezackte Kulisse. Ein Foto von 1947 zeigt den damals achtjährigen Rolf Haller auf San Romerio. Der Ort habe ihn seither nie mehr losgelassen, er versteht den Film auch als privates Vermächtnis an die Söhne und Enkel. Immer wieder kommen Kinder und Jugendliche darin vor, beim Reflektieren ihres Lebens, beim Schneiden wilden Spinats für Mammas Pizzoccheri, bei Arbeiten im Freien und im Gasthaus oder einfach im Spiel.

Nach zehn privaten kleinen Dokfilmen hat der Autor von 2008 bis 2013 den San-Romerio-Film recherchiert und gedreht. Aus Budgetgründen und mit handwerklicher Leidenschaft macht er als Amateur alles selber, Buch, den Grossteil der Kameraführung, Regie, Schnitt und Produktion, supervisioniert von befreundeten Professionellen. Für die Solothurner Filmtage wurde der Film nicht ausgewählt aber schon an zahlreichen Orten öffentlich gezeigt, so auch im August 2014 am internationalen Alpenfilmfestival in Pontresina, wo er als bester Schweizerbeitrag ausgezeichnet wurde.
Kein Folklorefilm mit den üblichen Klischees, vielmehr eine nachdenkliche Reportage über die Natur und die Menschen in einer immer schon abgelegenen Welt mit einer heute ungewissen Zukunft. Dokumente belegen neuerdings, dass die erstmals 1106 erwähnte Kirche, mit vermutlich älterem Fundament, der Stadt Tirano gehört. Bisher hatte stets die katholische Gemeinde Brusio die Kirche unterhalten. Begegnungsort oder Zankapfel, die Zusammenarbeit ist zwingend aber noch nicht geregelt. Denn auch dieser Bau ist gefährdet, wie die Alpwirtschaft auf 1793 Metern über Meer. Man müsste das Dach der Kirche abdichten, Drainagen erneuern, bröckelndes Mauerwerk und den Verputz festigen, vor allem aber die Stützmauer sichern, doch das Geld fehlt. Hoffnung kommt von einem Förderprogramm für die Restauration in Grenzregionen von der EU. Erstmals schützt eine Blache das Fundament am Abgrund vor Eis und Schnee.

Die Filmaufführung in der Sittermühle von Bischofszell war ein Erlebnis. Die ehemalige Pädiatrin Christine Homberger schuf hier einen einzigartigen Ort der Begegnung. Ihr Pädiaterkollege zeigte ein eindrückliches Werk, dem man noch viele Aufführungen wünscht. Der 57-minütige Film ist italienisch und schweizerdeutsch gesprochen, mit Vice-versa-Untertiteln.

Und übrigens kann man San Romerio nur zu Fuss bewältigen. Das schuldet man allen, die früher hier durchgezogen sind. Auch davon abgesehen, lohnt es sich!

Weitere Informationen zum Film und zur Alp San Romerio 